International Section

Arch. Esp. Urol., 60, 1 (95-96), 2007

\title{
A RARE COMPLICATION ASSOCIATED TO A SUPRAPUBIC CYSTOSTOMY: CATHETER KNOTTING.
}

\author{
Matias Villeta, Gonzalo Vitagliano y Octavio Castillo?.
}

From the Section of Endourology and Laparoscopic Urology. Department of Urology. Clínica Santa Maria and the Department of Urology, School of Medicine, Universidad de Chile?. Santiago de Chile. Chile.

Summary.- We report a rare case of spontaneous catheter knotting in the setting of a suprapubic cystostomy and also review previous reports and the rationale behind this event.

Keywords: Catheter. Suprapubic. Cystostomy.
Resumen.- Presentamos un caso clínico raro de anudado espontáneo de un catéter de cistostomía suprapúbica y revisamos notas clínicas previas analizando la causa de este evento.

Palabras clave: Catéter. Suprapúbico. Cistostomía.

\section{INTRODUCTION}

There are few reports on spontaneous knotting between catheters. This rare occurrence is especially unusual in urologic literature (1). We report a case of spontaneous knotting between a suprapubic catheter and a urethral catheter and discuss the rationale behind it.

\section{CASE REPORT}

A 70 year old male patient with a history of laparoscopic extraperitoneal prostatectomy had an episode of acute urinary retention after the urethral catheter had been removed on post operative day 5 . The patient was seen in the emergency room where urethral catheterization proved to be impossible. For this reason an $8 \mathrm{Fr}$ suprapubic catheter (Cistofix ${ }^{\circledR} 8$ $\mathrm{Fr}$ ) was put in place. After that, a Foley $20 \mathrm{Fr}$ catheter was inserted by means of endoscopy. Three days later a futile intent was made to withdraw the suprapubic catheter. It was evident that the catheter was trapped in the bladder and had become obstructed. 
After 7 days an attempt to remove the Foley catheter was made. However, this was not possible since the catheter's balloon would not deflate. Both vesical and suprapubic catheters were sectioned at skin and meatus level respectively. An ureterocystofibroscopy was performed. The urethral catheter's balloon proved to be filled and correctly placed into the bladder's lumen. Suprapubic puncture of the balloon was carried out with a needle under direct cystoscopic control. The urethral catheter was then removed. Upon removal the proximal knotting of the suprapubic catheter was evident (Figure 1).

\section{DISCUSSION}

In spite of the frequent simultaneous use of these catheters in daily urologic practice, reports in the literature about this rare complication are scarce (1). It is suspected that the most probable cause of this type of occurrence is the excessive introduction of the suprapubic catheter within the bladder. This would be motivated by the fear of losing the route of the suprapubic puncture. The majority of the reported cases are pediatric patients in which long, small caliber catheters with great flexibility are used in small bladders (1).

This situation must be suspected whenever, in the presence of these two types of catheters, the auto-fixation balloon of the Foley catheter can not be deflated. Another factor that has to be kept in mind is the permeability of the suprapubic catheter, this can indicate whether if it is tied or not $(2,3)$.

In order to ensure a less morbid procedure it is stressed that the resolution of this type of situation

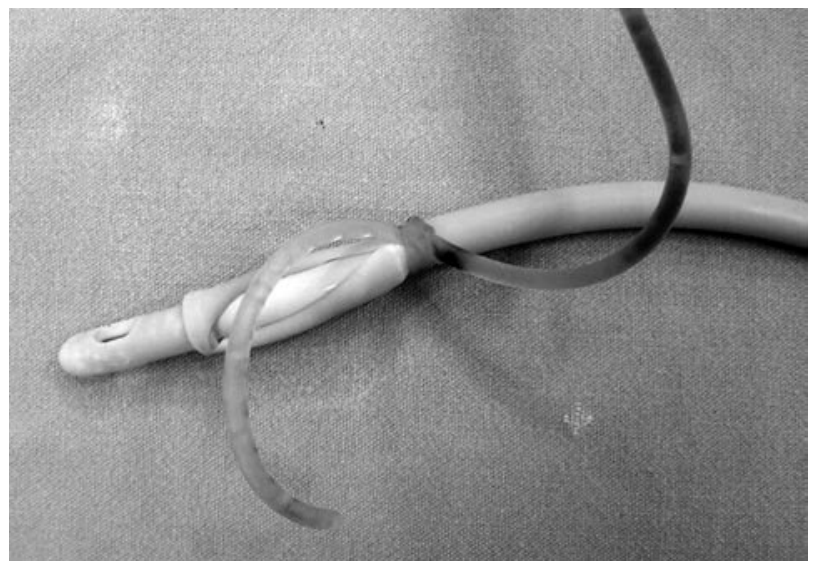

FIGURE 1. Suprapubic catheter knotted around urethral catheter. Note that the knot is behind the urethral catheter's punctured balloon. be carried out under endoscopic guidance and using anesthetic sedation and antibiotic prophylaxis. The suprapubic puncture of the urethral catheter's balloon is facilitated by means of ultrasound. We recommend that an endoscopic control be performed after the removal of the catheter due to the fact that the knot and the suprapubic catheter may injure the urethral mucosa.

\section{BIBLIOGRAFÍA y LECTURAS RECOMENDADAS (*lectura de interés $y^{* *}$ lectura fundamental)}

1. POLYCHRONIDIS, A.; KANTARTZI, K.; TOULOUPIDIS, S. y cols.: "A true knot in a suprapubic catheter around a urethral catheter: A rare complication". J. Urol. 165: 2001, 2001.

2. MISHRA, V.; KUMAR, A.; KAPOOR, R.: "Knotting of suprapubic epidural catheter with urethral filling tube. An unusual complication of pressureflow study". Br. J. Urol. 69: 329, 1992.

3. ARADA, I.; OZYAYLALI, I.: "An unusual complication of suprapubic catheterization with Cistofix: catheter knotting within the bladder". Int. J. Urol. 8: 188, 2001. 